\title{
EL PAISAJE LINGUISTICO DEL TURISMO COMO POLÍTICA Y REPRESENTACIÓN SOCIOCULTURAL EN PUERTO IGUAZÚ - ARGENTINA
}

\author{
Marlene Niehues Gasparin ${ }^{1}$ \\ Neiva Maria Jung ${ }^{2}$
}

Maria Elena Pires Santos ${ }^{3}$

\begin{abstract}
Resumen: Este artículo tiene por objetivo comprender como la construcción de las representaciones socioculturales se refleja en el paisaje lingüístico del turismo en los espacios públicos en la ciudad fronteriza de Puerto Iguazú, en Argentina. Para eso, buscamos reflexiones acerca del multilingüismo en el contexto de la globalización, considerando la tensión entre la mercantilización y el proceso de autenticación de las lenguas y culturas locales que componen el paisaje lingüístico. El material analizado fue colectado durante una observación de campo dentro de un trabajo etnográfico. Nuestra reflexión confirma la presencia del multilingüismo, dado que las etiquetas, los anuncios, los murales, es decir, los textos escritos en la vía pública, evidencian una tensión permanente entre la búsqueda por la autenticidad de las lenguas y culturas locales y la mercantilización.
\end{abstract}

Palabras clave: Paisaje Lingüístico. Multilinguísmo. Globalización. Mercantilización. Frontera.

\section{A PAISAGEM LINGUÍSTICA DO TURISMO COMO POLÍTICA E REPRESENTAÇÃO SOCIOCULTURAL EM PUERTO IGUAZÚ - ARGENTINA}

Resumo: O objetivo deste artigo é compreender como a construção de representações socioculturais se reflete na paisagem linguística do turismo em espaços públicos na cidade fronteiriça de Puerto Iguaçu, na Argentina. Para isso, buscamos reflexões sobre o multilinguísmo no contexto da globalização, considerando a tensão entre a mercantilização e o processo de autenticação das línguas e culturas locais que compõem a paisagem linguística. O material analisado foi gerado durante uma observação de campo em um trabalho etnográfico. Nossa reflexão confirma a presença do multilinguísmo, uma vez anúncios comerciais nas fachadas de lojas e em outdoors, escritos em muros, isto é, textos escritos em vias públicas, mostram uma tensão permanente entre a busca pela autenticidade das línguas e culturas locais e a mercantilização.

Palavras-chave: Paisagem linguística. Multilinguísmo. Globalização. Mercantilização. Fronteira.

1 Doctoranda en Letras por la Universidad Estadual de Maringá. E-mail: marlenegasparin@hotmail.com. CV: http://lattes. cnpq.br/8355428712626975.

2 Doctora en Letras por la Universidad Federal del Rio Grande do Sul. Profesora del Departamento de Lengua Portuguesa y del Programa de Posgrado en Letras (Maestría y Doctorado), de la Universidad Estadual de Maringá. E-mail: neiva.jung@ gmail.com. CV: http:/ /lattes.cnpq.br/9923668188972592

3 Doctora en Lingüística Aplicada por UNICAMP, profesora Sénior del Mestrado/Doctorado en Letras, de Maestría y Doctorado en Sociedad, Cultura y Fronteras y de la Maestría en Letras-Profletras, de UNIOESTE/PR. mepires@gmail.com. CV: http://lattes.cnpq.br/9605825897881271. 


\title{
THE LINGUISTIC LANDSCAPE OF TOURISM AS A POLITICALAND SOCIOCULTURAL REPRESENTATION IN PUERTO IGUAZU - ARGENTINA
}

\begin{abstract}
This article aims to understand how the construction of sociocultural representations is reflected in the linguistic landscape of tourism in public spaces in the border city of Puerto Iguazu, in Argentina. For this, we seek reflections on multilingualism in the context of globalization, considering the tension between the commodification and the authentication process of the local languages and cultures that make up the linguistic landscape. The analyzed material was collected during a field observation within an ethnographic work. Our reflection confirms the presence of multilingualism, given that labels, advertisements, murals, that is, texts written on public roads, show a permanent tension between the search for authenticity of local languages and cultures and commodification.
\end{abstract}

Keywords: Linguistic Landscape. Multilingualism. Globalization. Commodification. Border.

\section{Introducción}

La movilidad actual de las personas en todo el mundo globalizado no tiene precedentes en la historia humana. El capitalismo tardío, en especial después de la crisis de 2008 , creó nuevas demandas y productos y una de las características de esta nueva economía es el papel principal que el lenguaje empezó a desarrollar en todas las actividades (DA SILVA et al. 2007). El lenguaje, en términos de recursos lingüísticos instrumentales y simbólicos, se convierte en una mercancía en sí misma, en discursos que reafirman ideologías que lo conciben como una habilidad necesaria para el emprendimiento individual, así como una forma de agregar valor a otros productos (DUCHÊNE y HELLER, 2012; HELLER y DUCHÊNE, 2012, 2016).

Esta economía y movilidad ha estado fomentando, entre otros factores, la intensificación del turismo en todos los sectores y prácticamente en todos los países. Según Heller, Jawoeski y Thurlow (2014), el turismo, como una verdadera industria cultural, permite la implementación de recursos multilingües, en una tensión permanente entre la búsqueda por la autenticidad de las lenguas y culturas locales y la mercantilización, en que las lenguas pasan a ser definidas y organizadas como una mercancía en términos de producción, distribución y consumo en comparación con otras lenguas que se encuentran dentro de un mercado lingüístico. Así, el paisaje lingüístico del turismo se convierte en un espacio muy importante para observar las formas en que se dan los cambios sociales, políticos y culturales de la era contemporánea.

En esta perspectiva, reconociendo la centralidad del turismo en reinventar las economías y construir relaciones sociales mediadas por el lenguaje, proponemos en este artículo observar como esto sucede en la Triple Frontera Brasil/Paraguay/Argentina, cuyo principal aspecto económico es el turismo dirigido a las compras en la zona franca de Ciudad del Este/Paraguay y, a pesar de menor intensidad, también el turismo comercial y gastronómico en Puerto Iguazú/Argentina. Al lado de estos están, principalmente, los diversos puntos turísticos de la región, incluidas las Cataratas del Iguazú, que son las más atractivas para los turistas de todo el mundo. Las Cataratas del Iguazú, ubicadas en el río Iguazú, que divide la frontera entre Brasil y Argentina, la Unesco considera Patrimonio Natural de la Humanidad y una de las Nuevas 
Siete Maravillas de la Naturaleza. Solo en el lado brasileño de la frontera, por ejemplo, el Parque Iguazú - donde se encuentran las Cataratas del Iguazú - recibió, en 2019, 2,020,538 visitantes, provenientes de innúmeros países y ciudades brasileñas. Este flujo intermitente de personas, sumado a los habitantes provenientes de diferentes países y regiones brasileñas y a los residentes locales que se establecieron, aquí, a lo largo de su historia de colonización, configura una compleja y abundante pluralidad lingüística y cultural.

Focalizando la ciudad de Foz do Iguazú como componente de ese polo turístico constituido por la Tríplice Frontera, en un reciente estudio las autoras Silva, Pires Santos y Jung (2016) abordan un amplio análisis del multilingüismo y la política lingüística centrado en el paisaje lingüístico transfronterizo presente y recurrente, en la ciudad de Foz de Iguazú (Brasil). Así, discuten y señalan, cómo ese senario posibilitó una lectura semiótica local de dinámicas de frontera y de políticas translocales resultantes de procesos de la globalización (BLOMMAERT y RAMPTON, 2011; VERTOVEC, 2007). El análisis del paisaje lingüístico en este espacio evidenció, por un lado, la presencia de políticas linguísticas top-down, en textos en portugués e inglés en las tres mayores rotas turísticas de la ciudad, semiotizando así el turismo local y su status económico en el mundo globalizado. Por otro lado, el estudio reveló las políticas bottom-up, como la presencia de letreros escritos en árabe o con signos que remeten a la comunidad árabe local, especialmente en el centro y en el barrio Vila Portes, lo que constata las asimetrías en relación a la circulación de las lenguas en el espacio urbano, principalmente sobre las lenguas fronterizas, guaraní y español, casi invisibles en el paisaje lingüístico iguazuence. Ese estudio muestra, en síntesis, que el multilinguísmo y la superdiversidad son fenómenos muy comunes en esa región transfronteriza, resultantes de diferentes fatores históricos, políticos y económicos como las (i)migraciones, la porosidad de las fronteras y la globalización.

Por lo tanto, considerando la relevancia del lenguaje en el capitalismo tardío y en los estudios sobre las relaciones de las dinámicas lingüísticas en los espacios públicos compartidos, constituidos en prácticas sociales, este trabajo se centra, en el otro lado de la triple frontera, más precisamente, en la ciudad de Puerto Iguazú, en Argentina. Tenemos como objetivo comprender como la construcción de las representaciones socioculturales se refleja en el paisaje lingüístico del turismo, en los espacios públicos de la ciudad fronteriza de Puerto Iguazú, teniendo en cuenta la tensión entre la mercantilización y el proceso de autenticación de las lenguas y culturas locales. Los datos de ese paisaje fueron registrados durante un trabajo de investigación, entre los años 2016 y 2017, cuyo objetivo era observar, registrar y reflexionar sobre las lenguas que eran utilizadas en la interacción entre las personas, y la función social de las lenguas que eran visibles, en forma escrita, en los diferentes espacios sociales en forma de propagandas y anuncios comerciales.

Paratal fin, en este texto, en el primermomento ofrecemos, previamente, un recorrido sobre los enfoques teóricos acerca del multilinguísmo en paisaje lingǘstico que contribuye para la industria cultural del turismo, a su vez, considerando el impacto de la globalización y la superdiversidad en el capitalismo tardío. Luego, en el segundo apartado, analizamos, sociolingüísticamente, las lenguas y los grupos sociales y culturales, a través de algunos datos que constituyen el paisaje lingüístico de la ciudad y los valores agregados a productos culturales vendibles. En seguida, finalizamos con algunas consideraciones finales. 


\section{E1 paisaje lingüístico del turismo como representación sociocultural de formas contemporáneas de cambio económico, político y social}

Las ciudades y contextos urbanos en la contemporaneidad pasan por grandes movilidades sociales, lingüísticas, culturales y de identidad. ${ }^{4}$ El mundo globalizado se ha convertido en una red muy compleja de contextos que consisten en lazos materiales y simbólicos que a menudo son impredecibles, y es, precisamente, esta complejidadla que se debe estudiar y comprender (BLOMMAERT, 2012). Partimos del enfoque sociolingüístico que tiene en cuenta la "superdiversidad" (VERTOVEC, 2007), es decir, la diversificación de las diversidades en el contexto social, histórico-cultural y político del que forma parte el lenguaje.

Es perceptible que este nuevo marco de grandes flujos y profundos cambios sociales, impulsados por la globalización en el capitalismo tardío, reestructura y modifica el panorama de la diversidad lingüística y cultural, haciéndola bastante diversa y, a su vez, va deconstruyendo las nociones de lengua homogénea y estable, ya que considera la movilidad, complejidad e imprevisibilidad en las practicas sociales (BLOMMAERT, 2012, p. 11). Así, de homogéneo y estable, el lenguaje pasó a la movilidad y al hibridismo cultural y lingüístico, tornándose un recurso lingüístico y simbólico. Además, la movilidad ha traído consigo muchos cambios y complejidades nuevas que dan lugar a una dimensión de expectativas, que contribuyen para que las características lingüísticas sean dialécticas, constructivas y, por lo tanto, dinámicas (BLOMMAERT, 2012, p. 12).

Dadas las razones para pensar y comprender los estudios lingüísticos a la luz de la superdiversidad, es posible pensar que no hay campos autónomos

4 Conforme Hall (2005), las identidades, construidas en los discursos, son complejas, fluidas, contradictorias y están en continuo dislocamiento. de conocimiento que no estén relacionados con la cultura, la historia, la sociedad, las creencias, etc. y que los sujetos y los objetos no son a-históricos. Las prácticas discursivas en general "no son neutrales e implican elecciones ideológicas y políticas (intencionales o no) cruzadas por relaciones de poder, que causan diferentes efectos en el mundo social" (FABRÍCIO, 2006, p. 48). El lenguaje es una práctica social y, por esa razón, al analizarlo comprendemos, al mismo tiempo, la sociedad, la cultura y su relación con la economía.

Heller (2011, p. 27), a partir de sus estudios en una sociolingüística crítica, muestra que el lenguaje adquirió un papel central en la economía actual del capitalismo tardío. Dentro de esa idea, la economía, el lenguaje y la cultura se tornaron también mercaderías en un "mercado de performances y bienes culturales auténticos" en que "el lenguaje desempeña un papel importante en el proceso de autenticación". En ese caso, la función del lenguaje se torna, en muchos casos, un papel de agregar valor a un producto cultural vendible y, en el caso del turismo, el lenguaje se torna una puerta que señala las formas contemporáneas de cambio económico, político y social (HELLER; JAWORSKI; THURLOW, 2014). Algunas preguntas centrales a este respecto serían - "¿por qué algunos productos (y performance) y otros no, se consideran valiosos porque son auténticos"? y ¿"quién decide qué cuenta como autenticidad cultural y lingüística? (¿es el consumidor o el productor?)". Además de eso, ¿cómo un producto es constituido como auténtico? (DUCHÊNE; HELLER, 2012).

En esa perspectiva, el paisaje lingüístico se articula con la economía del turismo. Heller, Jaworsky y Thurlow (2014), a partir de una discusión sobre el lenguaje articulado con la nueva economía global, en el capitalismo tardío, afirman que el lenguaje y el turismo se han convertido en una brecha importante para articular cambios económicos, políticos y sociales. El turismo se 
ha convertido, según estos investigadores, en uno de los negocios internacionales más grandes del mundo, en una industria cultural global y un poderoso vehículo para la movilidad de dinero, de personas y de cultura, así como un dominio importante para los "flujos" siempre desiguales de materiales lingüísticos y otros recursos semióticos.

Esto significa que, para analizar el papel que juega el lenguaje en la economía actual, "no podemos ignorar el valor atribuido a las formas y prácticas lingüísticas o sus vínculos con todo tipo de actividades sociales y la circulación de recursos de todo tipo de orden social" (HELLER, 2010, p. 102). Es importante, por lo tanto, entender el turismo como un espacio discursivo centrado en los recursos que se producen, se valoran y se intercambian de manera desigual, pero también de manera creativa, representando socioculturalmente a los actores de manera diferente y a veces inesperada.

De esta forma, es posible percibir el flujo lingüístico y cultural reflexionando sobre los paisajes lingüísticos expuestos en diferentes contextos sociales, principalmente en el espacio del entorno público, donde se expande la noción de local y global en que se entrelazan diferentes lenguas y expresan posibilidades de comunicación. La materialización del paisaje lingüístico está motivada por innúmeras posibilidades y algunas de sus características (cf. DÍAZ, 2015) se ocupan del reflejo del bilingüismo social, del reflejo de las prácticas migratorias, del cosmopolitismo y/o la globalización, en las cuales existen marcas de internacionalización, de contextos históricos y turísticos, entre otros.

El estudio sobre el paisaje lingüístico tiene como referencia el trabajo de Landry y Bourhis (1997). Los autores plantearon un análisis acerca de la percepción francófona de un grupo de estudiantes canadienses observando sus actitudes ante los objetos en espacios públicos, tales como letreros comerciales, señalización, etc. Según Díaz (2015) y Burdick (2012), el trabajo buscó comprender la vitalidad etnolingüística donde el francés y el inglés han estado en contacto y en conflicto durante años. Actualmente, es una base teórica ampliamente discutida y presentada por muchos autores recientes (BURDICK, 2012; SHOHAMY, 2016; RODRIGUEZ, 2012; DALLA VECCHIA y JUNG, 2016; SOARES, LOMBARDI, SALGADO, 2016, entre otros), quienes muestran el amplio campo de análisis relacionado con la práctica lingüística en los contextos sociales situados.

El paisaje lingüístico, por lo tanto, se entiende, segun Diaz (2015), como un espejo de cómo las fronteras étnicas se muestran o emergen públicamente cuando diferentes sujetos o autores sociales interactúan entre sí y con otros en una determinada sociedad. La interpretación del paisaje lingüístico parte de la comprensión del espacio público como un lugar donde conviven intereses, argumentos y representaciones socioculturales muy diferentes.

Las representaciones socioculturales se construyen a través de negociaciones constantes, basadas en una cadena de significados que se orientan por visiones de mundo, intenciones, valores y creencias en contextos sociohistóricos y culturales, y luego se relacionan con las cuestiones de poder. Las representaciones son estrechamente correspondientes con las teorías sobre las identidades, lo que significa que quien tiene el poder de representar tiene el poder de definir las identidades, ya que estas se construyen, en prácticas discursivas, a través de diversas formas de representación (HALL, 2009; SILVA, 2000).

Del mismo modo, las autoras Soares, Lombardi y Salgado (2016) cuestionan y apuntan que determinadas preguntas como - ¿Que determina ese uso lingüístico tan diverso? ¿Quién contesta el lenguaje utilizado? ¿Quién lo escribió? ¿Para qué y para quién va dirigido? ¿Qué factores 
sociohistóricos llevaron a la existencia de ese lenguaje? ¿Cuáles son las implicaciones de estos usos lingüísticos en términos de repertorio comunicativo de las personas que residen o pasan por la ciudad? - son indagaciones que nos ayudan a comprender las prácticas discursivas representadas en los espacios públicos, entendiendo que el paisaje lingüístico está ideológicamente constituido y, por lo tanto, revela tales ideologías a través de diferentes manifestaciones (BURDICK, 2012).

Dalla Vecchia y Jung (2016), quienes analizaron el paisaje lingüístico presente en un contexto colonizado por suábios en el departamento del Paraná, señalan que el paisaje lingüístico local responde a las prácticas lingüísticas desarrolladas por/en diferentes contextos históricos. Aun así, según las autoras, citando a Gorter y Cenoz (2008), las marcas lingüísticas que se muestran en lenguas, como portugués y alemán estandarizado, a través de rótulos o por escrito en las vías públicas, determinan varias funciones, que a veces pueden ser más informativas, como las placas que demarcan los límites territoriales de un grupo lingüístico en relación a otros y, a veces simbólica, que demarcan el valor y el status de las lenguas y los grupos que representa en el contexto.

Se entiende, por lo tanto, que el lenguaje utilizado en medio de un contexto social no es ilegítimo o arbitrario, más bien, está motivado y orientado por varios factores de identidad social ${ }^{5}$, económico, político, etc. registrando mensajes sobre prácticas en estas sociedades (SOARES, LOMBARDI y SALGADO, 2016). Las autoras entienden que, dentro de una perspectiva social más amplia, un paisaje lingüístico está directamente

5 Como identidad social entendemos, según Vera y Valenzuela (2012), que trata en como el individuo, por medio de sus reflexiones, se percibe o se posiciona en la estructura social, espacio donde se incorporan, de forma dinámica, factores macroestructurales, microestructurales, e individuales. Por medio de ello, "los individuos internalizan en forma idiosincrática e individualizada las representaciones sociales propias de sus grupos de pertenencia o de referencia" (GIMÉNEZ, 1997, p. 15). relacionado con un paisaje sociohistórico y cultural, visto desde diferentes recursos lingüísticos.

Un paisaje urbano puede ser un reflejo de influencias, tendencias y restricciones pasadas y presentes y, al mismo tiempo transformadas por agencia y poder (BURDICK, 2012). Los procesos a través de los cuales el paisaje se realiza y transforma están inherentemente vinculados y ubicados dentro del lenguaje. Los letreros de las calles, los letreros comerciales, los folletos y los periódicos muestran palabras introducidas en el entorno, especialmente, diseñadas y construidas para un propósito, que son consumidas con una finalidad. De esta manera, los signos o las lenguas escritas no actúan en un espacio vacío o neutral, en cambio, existe una relación entre un signo, sus productores y sus consumidores. Aún, para Burdick (2012), la construcción del paisaje lingüístico no se limita a la señalización permanente, sino que debe incluir los llamados 'discursos en tránsito' o textos móviles transitorios, que acompañan el desplazamiento, el cambio y la naturaleza cambiante del lenguaje en diferentes contextos y para diferentes intereses.

Sáez y Castilho (2012), citados por Díaz (2015, p. 67), sintetizan la tipología del paisaje lingüístico como tres erres: el paisaje reglado (oficial y no oficial, pero con ciertas reglas de publicación); regable (posibilidad de que haya escritos que no estén sujetos a reglas y que permiten la libertad de expresión); y rebelde (refiriéndose, por ejemplo, al graffiti que está fuera de cualquier política de control lingüístico). Tratando de esta última tipología, el trabajo de Lecheta (2020) analizó datos escritos en murallas y paredes - manifestaciones lingüísticas en el espacio público urbano de Foz do Iguaçu y muestra, en términos de resultados, el carácter de resistencia de estas manifestaciones, cuando están presentes en espacios donde se "normatiza" la higienización, y que los transeúntes urbanos no son ajenos o distantes a las manifestaciones lingüísticas que componen este paisaje de la ciudad. 
Para el paisaje lingüístico que está reglado o regulado institucionalmente, Díaz (2015) lo llama de paisaje lingüístico 'contestado', es decir, funciona en respuesta a una intervención, ya sea educativa o política:

\begin{abstract}
El paisaje lingüístico se levanta sobre el espacio público, un lugar de todos donde a priori todos podemos intervenir, pero esa acción puede estar dirigida desde arriba. La regulación del paisaje lingüístico puede ir desde el plano más llamativo de la localización de los signos al ámbito más específico del código lingüístico que se emplea. En ese sentido, el paisaje visual de las ciudades puede ser partícipe de procesos intervencionistas amplios de planificación lingüística, que provocan que signos muy estudiados lingüísticamente convivan en el mismo espacio público con otros que desconozcan o rechacen esa clase de mediación (DIAZ, 2015, p. 67).
\end{abstract}

Tratando de planificación lingüística o no, el autor señala que en el mismo espacio público pueden coexistir signos regulados lingüísticamente y otros que no tienen control o mediación. De este modo, las reglamentaciones o las planificaciones muestran que el paisaje lingüístico no es una creación casual en espacios públicos, las lenguas escritas que aparecen tienen efectos en nuestras representaciones lingüísticas y en la constitución de la activación económica de un área o establecimiento determinado.

Según Cenoz y Gorter (2008), existen dos tipos de rotulo o textos públicos, los oficiales (topdown) y los privados (bottom-up). Los primeros reflejan a una política oficial, es decir, a un sistema reglado y controlado, que son textos institucionales, como notas, informativos, noticias, mientras el segundo se refiere a informaciones comerciales que pueden ser encontrados em diferentes establecimientos sin necesariamente tener en cuenta reglas especificadas. Estos serían los anuncios publicitarios, carteles, propagandas comerciales, informaciones escritas manual e informalmente, etc. y permiten, por lo tanto, mayor flexibilidad para la creación y manifestación pública.
De esta manera, para Srhir (2019, p. 15), a partir de las aciertas de Shohamy (2015), la interconexión del espacio con el paisaje lingüístico nos permite ser más críticos y "profundizar nuestras interpretaciones sobre el lenguaje como práctica espacial y acción humana con una dimensión política e ideológica muy transcendental". Además, es necesario enfocar ampliamente en el estudio del paisaje lingüístico autorizados o no, como políticas de lenguas, con el fin de garantizar mejor comprensión de esa dinámica que circunda el uso y la exposición de las lenguas.

Con base en los conceptos anteriores, presentamos a continuación, un conjunto de imágenes que pertenecen al paisaje lingüístico de Puerto Iguazú.

\section{E1 paisaje lingüístico del turismo de Puerto Iguazú:mercado, multilinguísmo y movilidad}

La ciudad de Puerto Iguazú fue fundada en $1943^{6}$. Las transacciones comerciales y el tránsito de personas entre Foz de Iguazú y Puerto Iguazú ocurrían por medio de balsas sobre el río Iguazú. Según Cury (2010), en 1928, la República Argentina compró el terreno para la creación del Parque Nacional y la instalación de la zona militar, además de delimitar el área urbana de Puerto Aguirre $^{7}$ con el Parque. En 1943, este lugar pasó a llamarse Iguazú, donde existen muchas otras formas de hacer fronteras (SANTOS, 2015, p. 01), por medio

$6 \mathrm{Al}$ igual que Puerto Iguaçu, Brasil tenía muchas ciudades fronterizas fundadas en ese período de tiempo, como Panambí, fundada en 1946, frente al Porto Vera Cruz (Rio Grande do Sul); Porto Xavier (Río Grande del Sur) (1629); la ciudad de Porto Mauá (Rio Grande do Sul), que se encuentra frente a Alba Posse, fundada en 1935, entre otros. Información disponible en: http://www.personal.psu.edu/ faculty $/ \mathrm{j} / \mathrm{m} / \mathrm{jml} 34 /$ Misiones.pdf.

$7 \mathrm{Al}$ principio, el nombre del municipio de Puerto Iguaçu era Puerto Aguirre, en honor a la turista Vitória Aguirre, quien hizo una gran donación para abrir un camino desde Puerto Iguaçu hasta las Cataratas (CURY, 2010). 
del dinamismo cultural, actividades comerciales y turísticas ${ }^{8}$, entre otras.

En 1982, después de que la frontera se abrió política y económicamente, los presidentes de las dos naciones plantearon la construcción del Puente Internacional Brasil/Argentina ${ }^{9}$, que se completó e inauguró en 1985. Por lo tanto, las diversas temáticas de esta frontera se han convertido en un campo fértil para las posibilidades de espacio para encuentros y diálogos.

Debido al factor histórico social, la ciudad de Puerto Iguazú contempla un espacio donde circulan y resignifican diferentes lenguas y culturas, comprendiendo que es un espacio de lucha social por demarcación territorial y, a la vez, es un contexto de frontera, lo que permite la intensificación de interacción transnacional. Algunos grupos autóctonos (o indígenas) conviven actualmente al lado de grandes redes hoteleras, las cuales se dieron como consecuencia de la llegada de Inversiones Externas Directas (IED), dentro de las reformas estructurales del 1990, permitiendo la entrada de grandes empresas nacionales y extranjeras, provocando un gran impacto a la comunidad local (GONZÁLEZ, RAMPELLO y DOMÍNGUEZ, 2017). Por eso, los grupos indígenas, como los de la localidad de yryapy, condicionados por los factores sociales, económicos, y por la falta de demandas sociales, ya no se encuentran tan consolidados en los espacios y en la movilidad social local. Por lo 8 Puerto Iguazú tiene atracciones relevantes con interés turístico, como el Marco de las Tres Fronteras; Parque nacional; La Aripuca, que consiste en un espacio de exhibición para troncos tomados de la selva misionera y que presenta espacios para la reflexión ambiental; M’bororê e Imágenes de la jungla; la casa de los pájaros (Guirá Ogá); Misiones jesuitas, entre otras (CURY, 2010).

9 Este puente se llamó inicialmente el Puente Internacional de la Fraternidad, también conocido como Puente Tancredo Neves (CURY, 2010; NUÑEZ, 2009). tanto, gracias a sus prácticas sociales y sus formas de vida, es posible tímidamente percibir su presencia, pero en situación más periférica.

El paisaje lingüístico en Puerto Iguazú es bastante diverso y situado. Mientras más nos dislocamos para el centro comercial, más aumenta nuestra percepción acerca del uso de las lenguas, que van intercalando espacios y toman posiciones específicas de acuerdo a su función y representación social en ese contexto. Las lenguas que encontramos escritas en los espacios públicos de la ciudad fueron el español (lengua oficial/local), el portugués, el guaraní y el inglés.

Como propósito de análisis del paisaje lingüístico en la ciudad, seleccionamos 11 imágenes de, aproximadamente 50 ejemplares registrados durante el recorrido por la región. En primer momento, es importante describir algunas representaciones de la dimensión sociohistórica del espacio, con vistas al proceso de "autenticación" (HELLER, JAWOESKI y THURLOW, 2014) de la cultura local, como los textos referentes al proceso histórico de la formación de la ciudad. En la plaza llamada "Paseo de la Identidad", ubicada en el centro de la ciudad, se encuentran expuestos algunos murales hechos por medio de la tecnica de esgrafiado, de los cuales destacamos dos, que retratan el proceso de las primeras actividades hechas como inicio de la demarcación, las costumbres y los rasgos de la idiosincrasia local. 

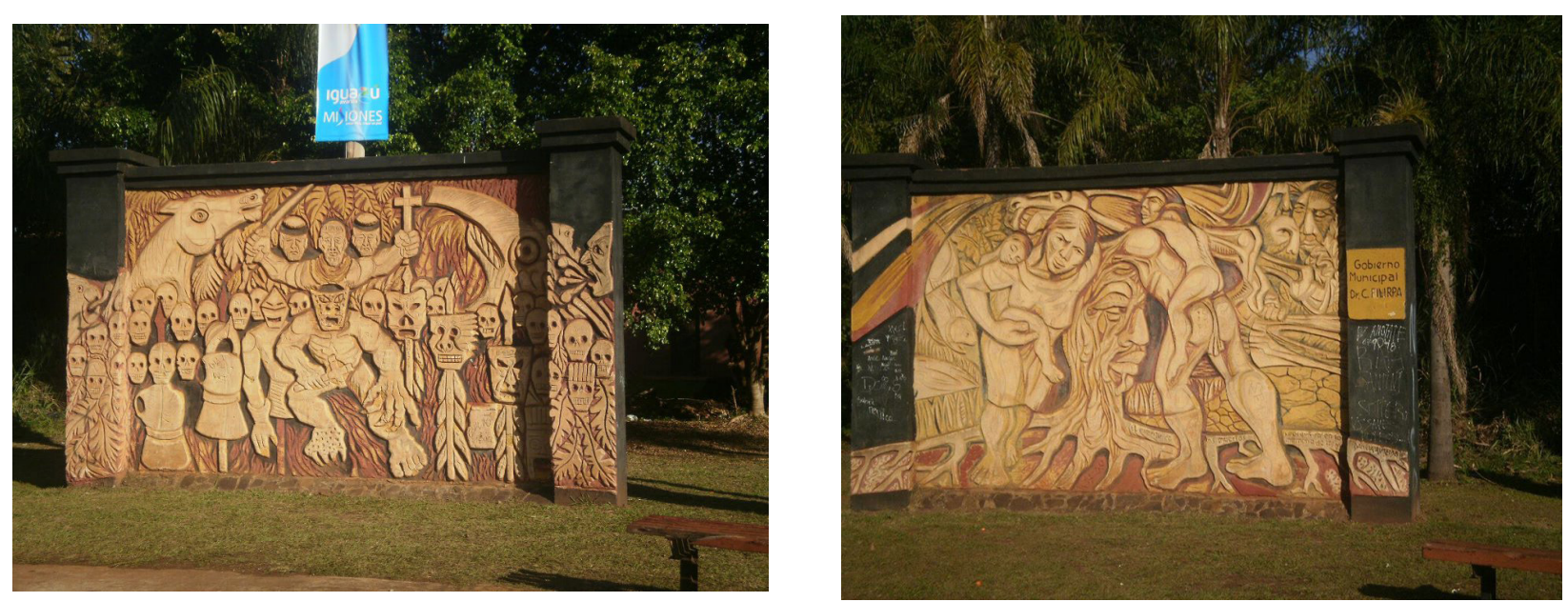

Imagen 1 y 2 - Plaza 'Paseo de la Identidad'.

Las dos imágenes (1 y 2), permanecen y conforman los espacios turísticos de la región y son diseños que intentan representar la identidad local y constituyen históricamente la formación étnica a partir de prácticas ligadas a la naturaleza, la religión y colonización. Es decir, traen elementos que muestran la relación de contacto establecida entre los pueblos originarios (Mbya guaraní) y los colonizadores a través de sus prácticas sociales y religiosas.

De este modo, esta autenticación dada al patrimonio cultural y a la identidad local, trae memoria de lo que se constituyó en las primeras prácticas colonizadoras juntamente con los grupos originarios que poblaban la región. Entonces, el ‘lenguaje de estos murales’ (LEVINTON, 2009) intentan preservar elementos históricos relacionados a la llegada de los que estarían promoviendo nuevas estrategias con el fin de demarcar espacios sociales, culturales y religiosos.

Pasando para otro punto de análisis, en Puerto Iguazú, la lengua de la mayoría de los habitantes es el español, que es la lengua oficial del país, pero, a menudo, se percibe el uso de otras lenguas, principalmente el portugués. La intensificación de la lengua portuguesa en ese espacio social sucede debido al factor económico, ya que la mayoría de los clientes extranjeros son brasileños, especialmente, de Foz de Iguazú, por la proximidad y por el hábito de cruzar la frontera en busca de productos argentinos, como dulces, frutas, medialunas o para compartir buenos vinos.

Durante algunas charlas con personas locales, como comerciantes/vendedores ambulantes y clientes de la región, estos señalaron que, por más que la lengua portuguesa sea la lengua extranjera que más se utiliza en ese entorno comercial y turístico, ellos no hacen el intento de hablar la lengua del turista o cliente brasileño, evidenciando la tensión entre la mercantilización y el proceso de autenticación de lenguas y culturas locales. Según estos locales, "hablar portugués es despreciar el idioma español, el idioma del país, que el visitante debe hacer el ajuste", mientras que hablar español es una forma de resistencia en vista del hecho de que cuando vienen a Brasil "ningún brasileño intenta comunicarse en español con ellos" (Registro de Campo, junio, 2017). Con eso, es posible inferir que el portugués básicamente no es utilizado como lengua de interacción por parte del vendedor o comerciante.

Sabemos que las prácticas de lenguaje constituyen una estrategia para monetizar el potencial turístico muy valorado en la esfera comercial, es decir, la busca por facilitar la interacción es más eficiente para las prácticas comerciales, en que alternan su valor de uso y valor de cambio. Sin embargo, en este 
contexto ocurre también el proceso de autenticación, representado por convicción de mantener la lengua nacional como la lengua que los mantienen demarcados de los brasileños. Pero en cambio, el portugués es intensificado en el paisaje lingüístico del turismo de Puerto Iguazú, juntamente con la lengua española, como veremos en los ejemplos que siguen.

Hemos observado que la mayoría de los carteles o anuncios comerciales presentan una escritura en que hibridizan el español con el portugués. Además, todos se ubican en el centro de la ciudad, demarcando una rota de compras del brasileño. La imagen 3, a seguir, anuncia tanto bocadillos típicamente brasileños como argentinos, en las respectivas lenguas.

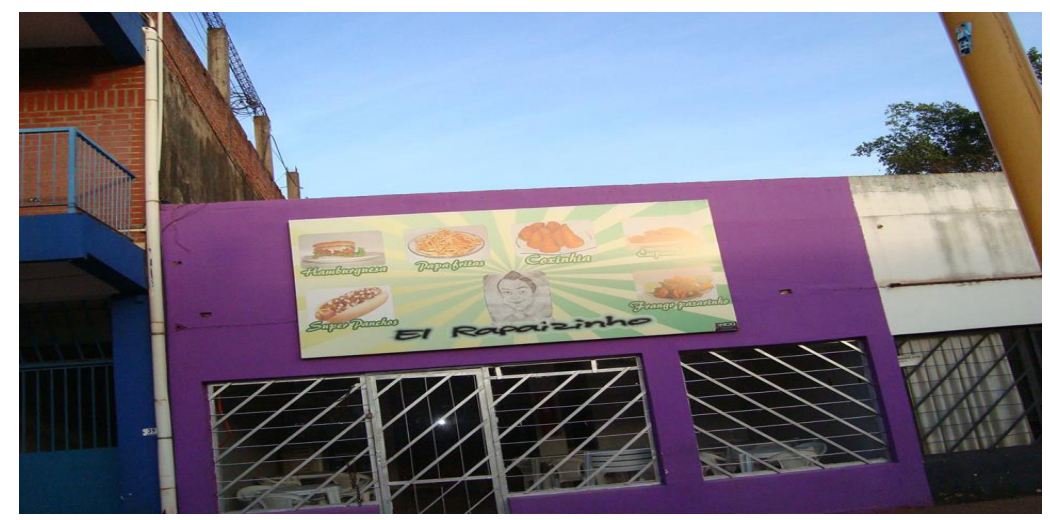

Imagen 3 - Restaurante El Rapaizinho

Esta imagen anuncia un restaurante o comedor con el nombre ‘El Rapaizinho' cuyo nombre marca una particularidad brasileña, que proviene de la palabra - rapaz, traducido como muchacho. Podemos inferir esta relación o asimilación del uso de este recurso debido a la presencia constante de flujos de brasileños en la región, entendiendo que la palabra tiene un fuerte sentido de representación sociocultural atribuido a las personas de nacionalidad brasileña. Además, anuncia los siguientes bocadillos: en español, - "Super pancho, Hamburguesa, Papa fritas - y en portugués, - Coxinha, Espetinho y Frango passarinho". Al monetizar las lenguas y las culturas, el multilingüismo presente en este paisaje turístico puede entenderse, no como dos monolingües paralelos, sino como un entrelazamiento de expresiones y palabras que se recontextualizan para construir significados que extrapolan la dicotomización de las lenguas y evidencian la tensión entre la mercantilización y la autenticación.

La imagen siguiente (4), expuesta en una acera, con palabras escritas en portugués, anuncia los productos que allí son vendidos, luego abajo, indica con una flecha la dirección del comercio.

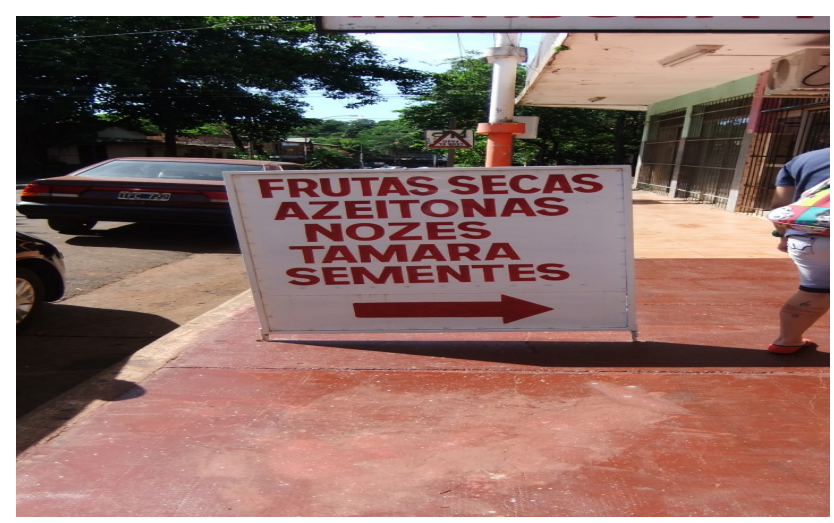

Imagen 4 - Comercio de alimentos variados 
La imagen (4) es un anuncio localizado frente a un establecimiento de ventas de alimentos variados (frutas deshidratadas, semillas, granulados, etc.) que, a su vez, es un lugar muy visitado por los brasileños. Es posible observar que todas las palabras relacionadas a los productos están escritas en portugués que, por lo tanto, son bastante semejantes al español: frutas secas (frutas secas); azeitonas (aceitunas); nozes (nueces); sementes (semillas). De esta forma, inferimos que existe una mercantilización de las prácticas lingüísticas con fines de lucro, revelando la intención de que los compradores brasileños se sientan atraídos por su propia lengua.

Abajo, en la imagen 5 tenemos un anuncio, de un lugar también bastante frecuentado debido a la comercialización de salames, dulces de leche y vinos.

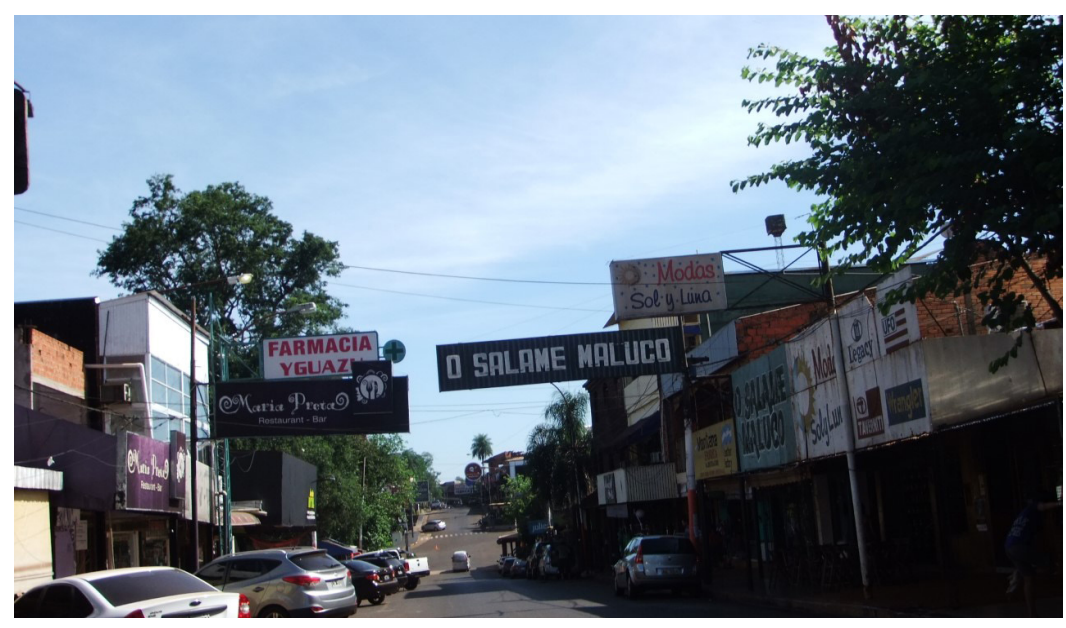

Imagen 5 - Comercio de salame

Asimismo, al llamar la atención por el uso de la lengua portuguesa considerando a los respectivos clientes, también llama la atención el estilo lingüístico utilizado, es decir, la declaración atribuye un efecto de sentido cómico: o salame maluco (el salame loco). En este sentido, Díaz (2015) y Rodríguez, (2012) afirman que la elevación visual del lenguaje utilizado en un lugar determinado tiene una intencionalidad y capacidad de llamar la atención de quienes lo ven a través de textos personalizados, cuidando el tamaño de fuente, el color y la posición relativa que ocupa en el espacio.

La imagen 6 es otro ejemplo de cómo la lengua portuguesa está fuertemente marcada en la ciudad.

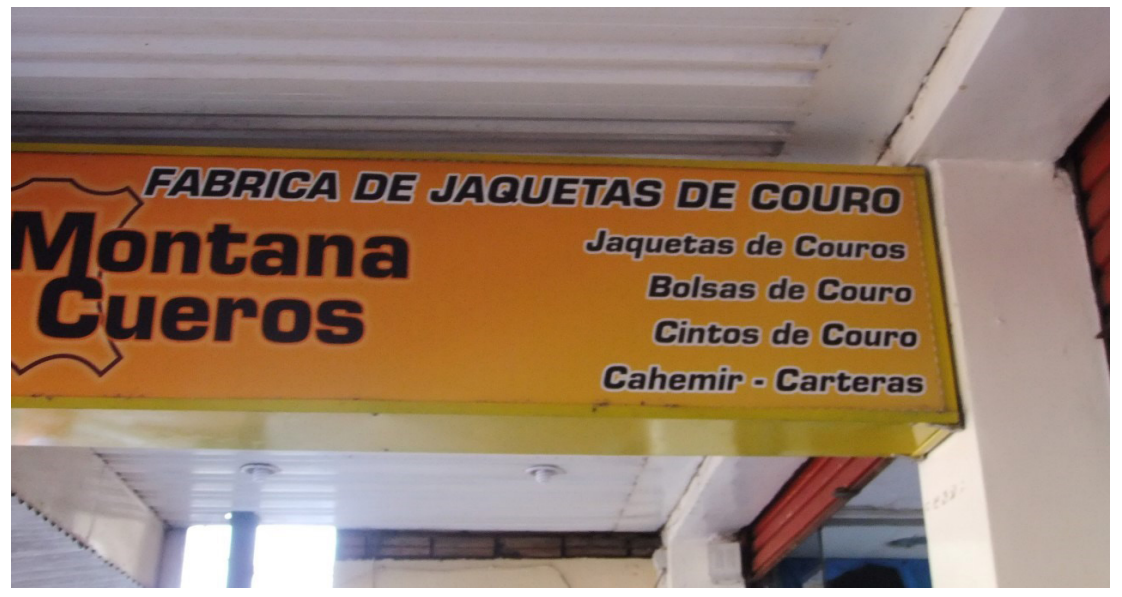

Imagen 6 - Fábrica de jaqueta de cuero 
Es un anuncio de fabricación de chaquetas de cuero y, como se nota, las únicas palabras escritas en español es el nombre del establecimiento (Montana Cueros), Cahemire y carteras, por lo que todas las demás palabras, que especifican a los productos, están escritas en portugués.

El hecho de utilizar el portugués con mayor frecuencia en relación a otras lenguas extranjeras muestra una rota de compras de brasileños, como señalamos anteriormente, ya que es una lengua de mayor contacto social y, principalmente, económico que visa a determinado perfil consumidor, o brasileño. Son imágenes que muestran una escritura en español y portugués y que sirven para mostrar que hay un mercado lingüístico y económico (HELLER, 2016), que hace prevalecer esas dos lenguas en los centros comerciales y visibiliza la representación sociocultural de las personas brasileñas como posibles compradores de sus productos. De esta forma, es una estratégica de esta nueva economía global que utiliza el lenguaje para agregar valor a productos culturales, como en este caso, bocadillos, productos de cuero, vino, dulce de leche, semillas, entre otros. Entendemos que, en un contexto multilingüe, elegir una lengua para la comunicación pública, no se aplica por la necesidad de ser comprendido necesariamente, se aplica por factores económicos, de identidad de un grupo social especifico, como forma de captar atención (RODRIGUEZ, 2012) y de evidenciar segregaciones sociales, luchas y desigualdades dentro de una economía del turismo (HELLER; JAWORSKY y THURLOW, 2014).

Por otra parte, señalizando para otra rota, la de los turistas probablemente extranjeros, encontramos también, en el paisaje, la presencia del inglés. La imagen 7 fue registrada del escaparate de un establecimiento comercial que trae la palabra del español - tire, (puxar) junto con inglés - pull (puxar).

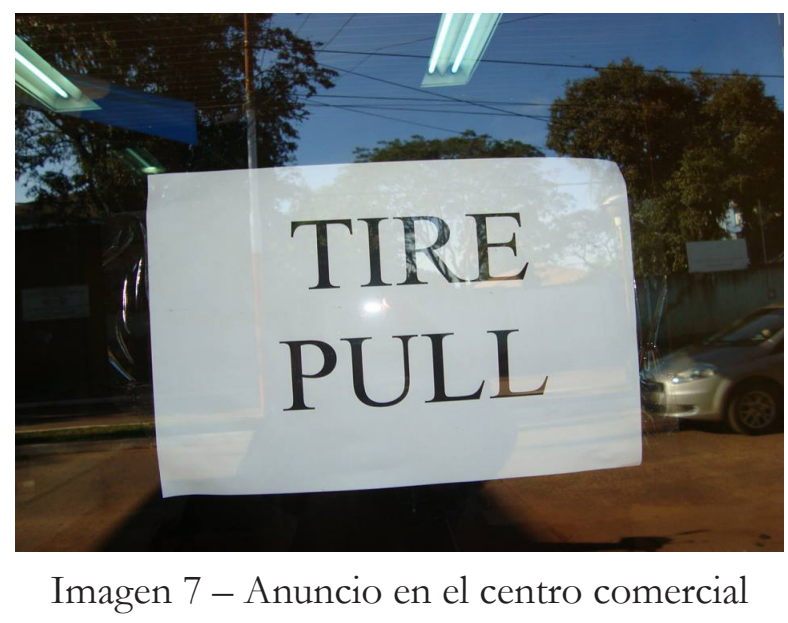

Entendemos que el enunciado puede, por un lado, apuntar para los turistas que hablan inglés y, por otro lado, servir para producir un efecto social y semiótico, dado la representación del inglés como lengua de status social y de internacionalización. Para más, esas prácticas linguísticas, ese nuevo modelo de comunicación y reproducción del espacio (SRHIR y ADIL, 2018), producen efectos simbólicos y nos permiten identificar la relevancia global de lo local, que es una de las manifestaciones de la globalización y la "translocación” (VERTOVEC, 2007 apud SRHIR y ADIL, 2018).

En la imagen 8 a seguir, aparecen las tres lenguas - español, portugués e inglés. La mayoría de las palabras están escritas en portugués para identificar los productos - couro (cuero); sobretudo (sobretodo); blusas de lâ (saco de lana), mientras que en español se limita a la palabra cachemir. 


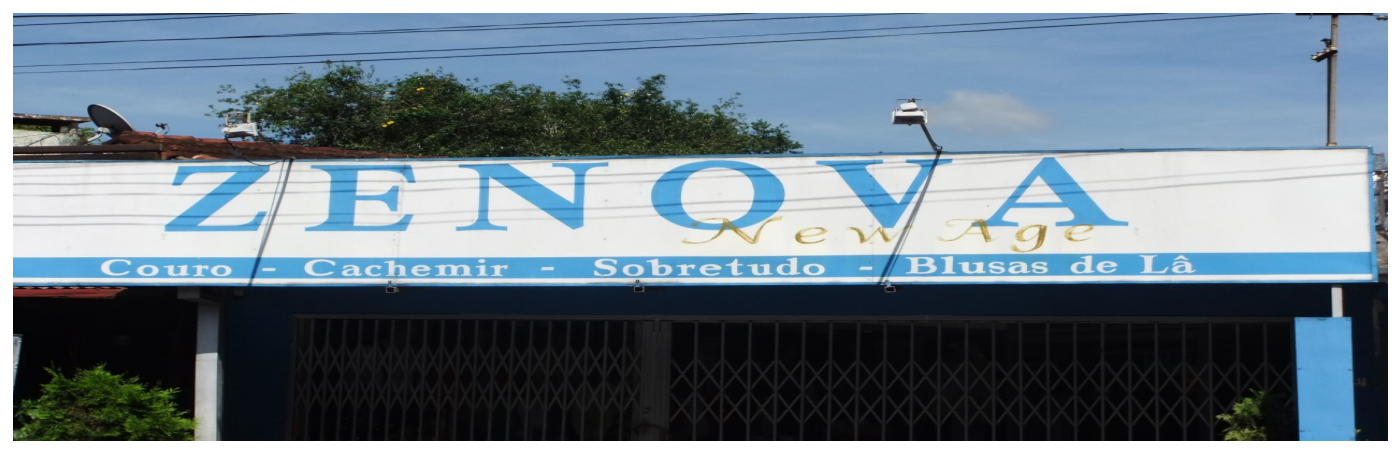

Imagen 8 - Placa del centro comercial

El uso del idioma inglés - new age (nueva era), se refiere más a una mercantilización del lenguaje que para informar, a diferencia del uso del portugués, que, en este caso, se refiere a productos que se vende en esa tienda. La lengua inglesa, aquí en este contexto, no configura necesariamente una función informativa sirviendo de comunicación para las personas locales y turistas, más bien posee una importante representación, con un valor de internacionalización y sofisticación (CENOZ y GORTER, 2008). El inglés, en este ejemplo aparece asociado al estilo de modernidad con fines estilísticos y no, necesariamente, para fines de información.

En cuanto a las opciones lexicales, o incluso, las opciones lingüísticas que tienen valores simbólicos o que tienen un valor atractivo, son determinadas por los actores de dicha información. Aun así, la existencia de factores externos permite reproducir el mismo lenguaje en otros contextos. Según Díaz (2015), debemos separar, por un lado, el lenguaje producido localmente (signos locales), los llamados - in situ - y los producidos para una distribución supralocal, es decir, producidos en un contexto global (signos globales), que pertenecen a diferentes corporaciones que cuentan con una marca o emblema. Por lo tanto, el primer grupo nos revela las preferencias lingüísticas de un grupo y puede representar una comunidad presente en el entorno, mientras que la elección del segundo grupo lingüístico se puede utilizar para enriquecer, de manera cualitativa o cuantitativa, el paisaje lingüístico, ya que se repite de la misma manera en muchas ciudades que tienen el mismo producto o negocio.

Así como en la imagen 8, en la imagen 9, que mostramos abajo, también aparecen el español, el portugués y el inglés, con la finalidad de la difusión del restaurante Doña María.

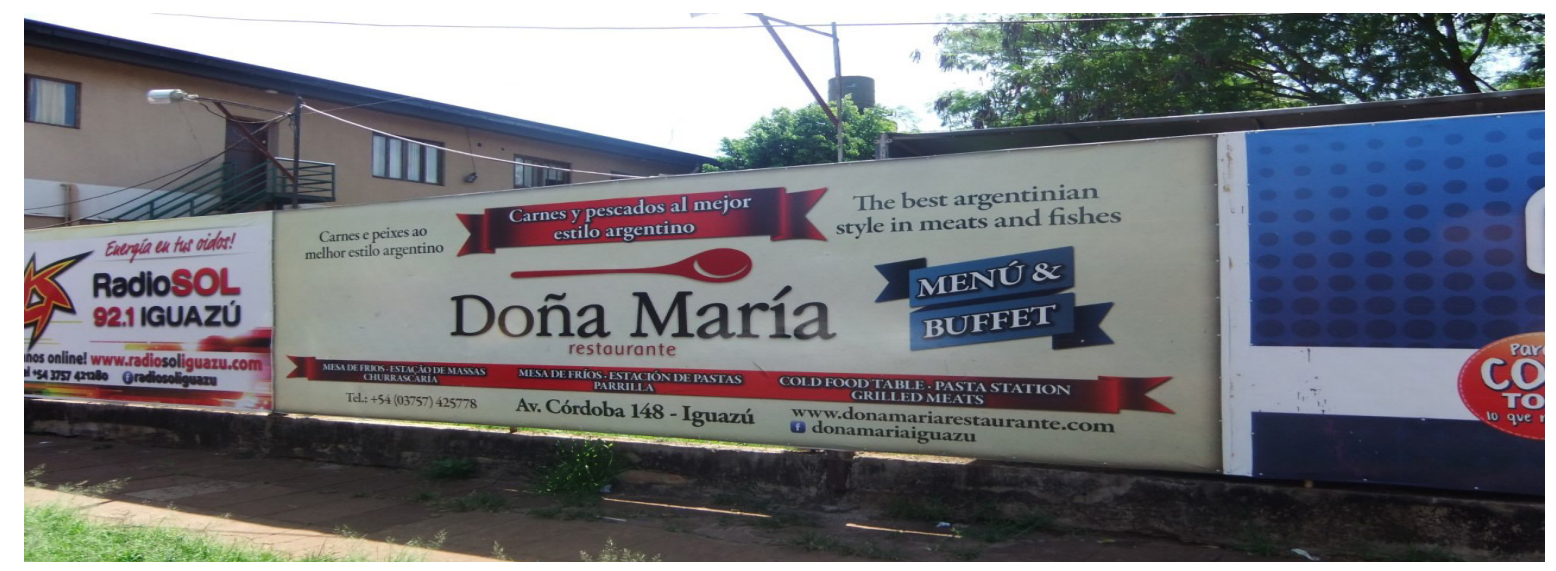

Imagen 9 - Restaurante Doña María 
La utilización de las tres lenguas - español, portugués e inglés - en formato de traducción como monolingües paralelos, amplía el alcance de los posibles turistas, con la autenticación de las lenguas locales, acrecida del inglés como una forma de agregar valor simbólico a la mercantilización de la lengua, en este contexto. Traer el inglés a este escenario también puede significar una expectativa de que los turistas sentirán "un agradable sentimiento de pertenencia a una comunidad imaginada de turistas y ciudadanos cosmopolitas globales" (HELLER, JAWOESKI y THURLOW, 2014, p. 437).

Objetivando resaltar también la autenticación de la cultura local, la imagen informa a los clientes y visitantes que el establecimiento presta servicio de 'Carnes y pescados al mejor estilo argentino'. Sin embargo, la demarcación y formulación lingüística reforzada en el centro del anuncio, en color rojo y en lengua española, nos muestra a quienes precisamente va dirigido el mensaje, una vez que la escritura en español sobresale al inglés y al portugués que permanecen en la parte lateral, en escrituras menores.

Por último y señalando para otra rota del turismo, otro paisaje que nos llamó la atención es la presencia de la lengua guaraní. Esta lengua, diferente de las localizaciones públicas en que se encuentran las demás imágenes analizadas anteriormente, está restringida a espacios más distantes del centro comercial, donde se venden artesanías indígenas del grupo Mbya Guarani. En ese local quedan concentrados mayoritariamente los grupos indígenas vendiendo sus productos artesanales.
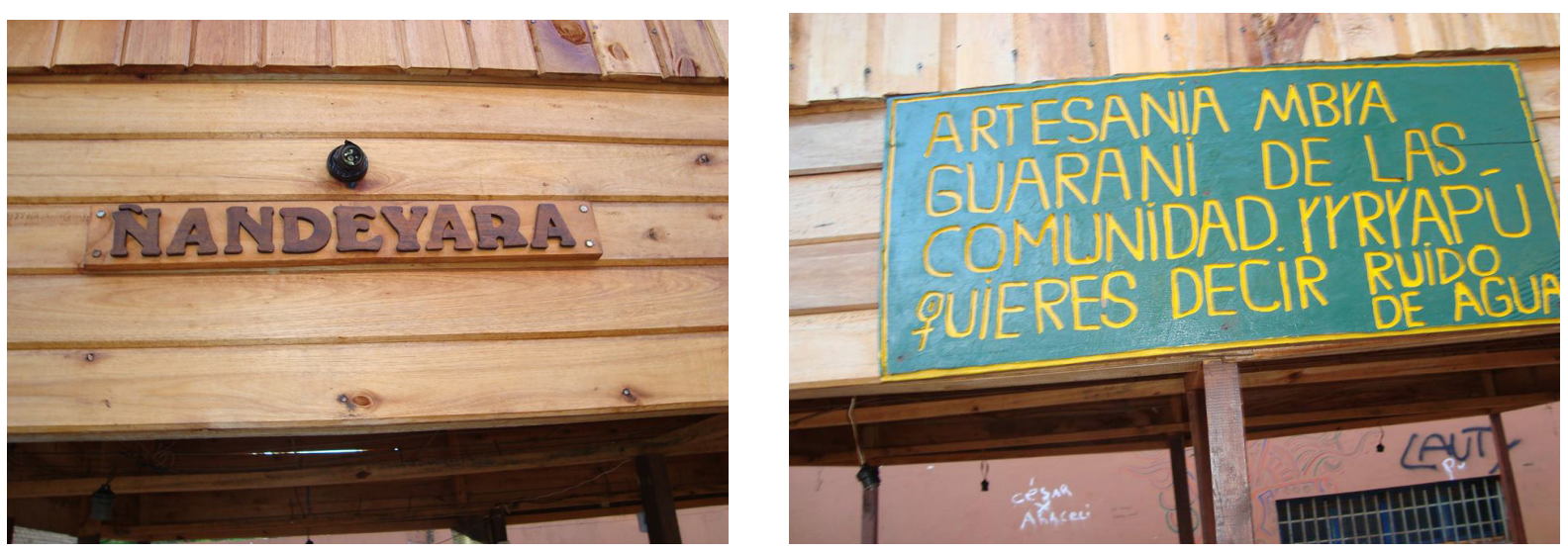

Imagen 10 y 11 - Placa de venta de productos artesanales

En la imagen 10, la palabra - Nandeyara - que se traduce como "Dios", nos hace inferir que la tienda mantiene rasgos de la cultura indígena, inclusive por el nombre atribuido al local, el cual tiene una relación con la religiosidad de ese grupo específico. En la figura 11, tenemos un manuscrito que presenta una escritura híbrida entre el guaraní y el español. La placa especifica el lugar de origen de los productos y artesanías, es decir, los productos son elaborados en la comunidad 'yryapu', cuyo significado es 'sonido del agua', como se destaca en el texto, en español (ruido de agua). Es notable que la lengua española, en esa imagen, sirve como puente que permite al interlocutor o migrante comprender la lengua guaraní.

Quedó evidente que la lengua guaraní ocupa un lugar distanciado del espacio de movilidad económica, por ejemplo, del centro comercial que sirve de trayecto para brasileños. Por lo tanto, al utilizar la lengua española en este anuncio, se tiene la intercesión de ser comprendido, de manifestar y reivindicar un lugar en ese espacio comercial más amplio, un lugar para quienes la utilizan y un lugar de existencia, es decir, muestra la lucha de los hablantes en relación a la estructura social.

Además, es posible observar que en la imagen 11, las informaciones están escritas manualmente y con desvíos de la norma escrita formal del español, como la falta de concordancia entre las palabras 
(las comunidad - quieres decir). Entendemos, por un lado, que es una amuestra de carencia de recursos disponibles para la elaboración del anuncio, como de formulaciones digitales, de un apoyo institucional y de recursos más modernos, como es recurrente en los demás ejemplos aquí expuestos, que ocupan un lugar más privilegiado. Por otro lado, refuerza también la presencia de la autenticación de las prácticas culturales y del lenguaje local, como forma de significar para el turista que estas son la cultura y el lenguaje de los artistas locales legítimos, es decir, esto es el valor de las lenguas y de las tradiciones locales.

Además, sobre esto, Cenoz y Gorter (2017) afirman que la dinámica del paisaje lingüístico referente a las lenguas minorizadas que se encuentran en los espacios públicos, debe ser puesta en discusión, pues refleja la relación de poder existente con otras lenguas elevadas a mayor prestigio social. En el caso de Puerto Iguazú, las imágenes apuntan para quien vende qué y para quien. El uso de las lenguas apunta a rutas turísticas de grupos sociales. Como Heller, Jawoeski y Thurlow (2014) nos advierten, el lenguaje presente en el paisaje lingüístico del turismo tiene un papel importante en la construcción de las relaciones sociales y las desigualdades sociales.

Estos ejemplos, por más tímidos que estén y con poca socialización, por un lado, muestran la relación de poder entre el uso y la representación de las lenguas y, por otro lado, manifiestan el carácter turístico de la región, donde, inclusive, por ese medio, existe esa manifestación de la lengua minoritaria o minorizada que es el guaraní, utilizado por ese determinado grupo social que constituyen los factores históricos territoriales de la región. De este modo, el paisaje lingüístico se materializa en la escritura, es decir, estamos frente de enunciados que utilizan el sistema gráfico que pueden presentar rasgos del lenguaje oral (DÍAZ, 2015), y dar paso a las innovaciones léxicas, a las tendencias gráficas o características interlingüísticas que otros textos vinculados a la presión normativa de la corrección pueden ocultar.

A partir de estos paisajes o recursos lingüísticos, reconocemos la presencia de la identidad indígena que existe en la determinada región y que es parte de la formación de la cultura e identidad de la ciudad y que le da visibilidad a la cultura y a la lengua guaraní, y que se manifiesta como una forma más nacionalista que visa vender la historia local para brasileños y extranjeros. La presencia de la cultura de estos grupos indígenas, por más reducidos que se vean en las manifestaciones públicas, nos evidencian un pasado de una tierra ya ocupada antes de la colonización, diferente de como muestran los discursos oficiales que apagan la memoria del pasado de ese local y que muestran heroico de los pioneros en la formación social harmónica en ese espacio social (HORII, 2014).

En suma, la presencia de las diferentes lenguas proyecta la colectividad y conectividad entre las personas que circulan en ese contexto social. Todavía, no cabe dudas que cada lengua ejerce un rol de representación social y económica y que, por lo tanto, refleja una relación de jerarquía entre ellas. Reflexionar sobre el paisaje lingüístico es, entonces, comprender la mobilidad y como la economía local reconoce esa movilidad y anuncia sus productos y su historia para participar de la economía del turismo.

\section{Conclusiones}

En sentido general, después de nuestra breve consideración analítica con respecto a la comprensión de las representaciones socioculturales en el paisaje lingüístico del turismo de Puerto Iguazú, mostramos que es posible comprender que el paisaje lingüístico es un conjunto de logros escritos que vemos expuestos en un entorno público determinado y que dice muchos de las 
personas que allí viven y circulan, es decir, que las prácticas culturales y de lenguaje están articuladas con la economía del turismo local, a partir de una tensión entre la mercantilización y el proceso de autenticación local.

Nuestro análisis muestra que las lenguas que mayormente se encuentran en los espacios públicos, en la parte central y comercial de la ciudad, son el español y el portugués, esta última como la lengua extranjera más latente en el espacio público, debido, necesariamente a la fuerte presencia de consumidores brasileños que vienen en la región. El inglés se ve mínimamente como indicador de información y también de consumo, por lo tanto, sirve como símbolo de internacionalización. Mientras que la lengua guaraní es visible solamente en espacio donde se localizan los grupos que se dedican a la venta de las artesanías y que intentan tornar visibles y vender sus productos de forma creativa.

Mirar políticamente para estos paisajes lingüísticos es reflexionar, por un lado, sobre las relaciones transfronterizas dadas por los habitantes que son legados sociohistóricos que no deben ser omisos o desvalidos y, por otro lado, como la economía del turismo se apropió de esto para vender "nuevos" productos, con valor agregado, dentro de una nueva dinámica del capitalismo.

La región es creada y constituida a partir de factores y prácticas históricas y sociales distintas, y que algunos de esos procesos pueden ser percibidos en los registros lingüísticos que existen y desempeñan funciones comunicativas que marcan las luchas sociales y la dinámica social local, que evidencia una jerarquización de las lenguas y de los sujetos que de ellas se disponen, evidenciando un contexto donde se hace desigualmente cambios económicos que implican cambios culturales, cambios de vidas, es decir, el paisaje muestra un contexto multilingüe y multicultural capturado por la economía global del turismo.

\section{Referencias bibliográficas}

BLOMMAERT, J. Ethnography, Super-diversity and Linguistic Landscapes. 2012.

BLOMMAERT, J. e RAMPTON, B. Language and Superdiversity Diversities, 13(2), 122, 2011.

BURDICK, Christa. Mobility and Language in Place: A Linguistic Landscape of Language Commodification. University of Massachusetts, 2012. Disponible en: http://scholarworks.umass. edu/chess_student_research/7/.

CENOZ e GORTER. El estudio del paisaje linguístico. Tradução, Hizkunea. UvA-DARE is a service provided by the library of the University of Amsterdam, 2008.

CURY. M. J. Territorialidades transfronteiriças do Iguassu (TTI): interconexões, interdependências e interpenetrações nas cidades da tríplice fronteira - Foz do Iguaçu (BR), Ciudad del Leste (PY) e Puerto Iguazú (AR). CURITIBA, 2010.

DA SILVA, E., MCLAUGHLIN, M., e RICHARDS, M. (2007). Bilingualism and the globalized new economy: The commodification of language and identity. In M. Heller (Ed.), Bilingualism: A social approach (pp. 183-206). Basingstoke, UK and New York, NY: Palgrave MacMillan.

DALLA VECCHIA e JUNG. Paisagem linguística em um contexto suábio-brasileiro: mobilidade e representação de uma comunidade "germânica". Revista da Anpoll no 40, p. 115-128, Florianópolis, 2016.

DÍAZ, Noemi. El paisaje lingüístico o la construcción de un espacio híbrido en el Instituto Cervantes de París. Estudios interlingüísticos, 3, p. 89-104, 2015.

DUCHÊNE, A.; HELLER, M. (orgs.). (2012). Language in late capitalism: Pride and profit. New York: Routledge. 
GIMÉNEZ, G. (1997). Materiales para una teoría de las Identidades Sociales. Instituto de Investigaciones Sociales, México: UNAM. Acceso en 15 de abril, 2020. Disponible en http://www. gimenez.com.mx/index.html.

HALL, S. A Identidade Cultural na Pósmodernidade. Rio de Janeiro, DP\&A. 2005.

HELLER, M.; DUCHÊNE, A. (2016). Treating language as an economic resource: Discourse, data and debate. In: Coupland, N. (org.), Sociolinguistics: Theoretical debates. Cambridge: Cambridge University Press, pp. 139-156.

HELLER, M.; JAWORSKI, A.; THURLOW, C. Introduction: Sociolinguistics and tourism mobilities, markets, multilingualism. Journal of Sociolinguistics, 18/4, 2014, p. 425-458.

HELLER, M. Paths to Post-Nationalism: A Critical Ethnography of Language and Identity. New York, NY: Oxford University Press, 2011.

HELLER, M. The Commodification of Language. Annual Review of Anthropology, 2010, 39, 101114. Disponible en: anthro.annualreviews.org.

HORII A. K. Dillenburg. Território guarani na tríplice fronteira: fragmentos que resistem no espaçotempo. Revista IDEAÇÃO. Volume 16 Número 24 - Jul/Dez 2014 - pp. 121-141.

LECHETA, M. Paisagem linguística urbana na fronteira: dinâmicas e identidades sociais. 2020. Dissertação (Mestrado em Sociedade, Cultura e Fronteira) - Universidade EStadual do Oeste do Paraná - Campus de Foz do Iguaçu, Foz do Iguaçu, 2020.

LEVINTON, Noberto. El espacio jesuíticoguaraní: la formación de una región cultural. Asunción Paraguay: Asunción: CEADUC, 2009.

NUÑEZ, Ana Carolina (2009). En Puerto Iguazú, Misiones (Arg.). Ordenamiento territorial y políticas hegemónicas. Una visión crítica. XXVII Congreso de la Asociación Latinoamericana de Sociología. VIII Jornadas de Sociología de la Universidad de Buenos Aires, (2009).
PIRES-SANTOS, M. E. Narrativas de identidades: a linguagem como lugar de (in)visibilização. In: PEREIRA, D. A. (Org.). Cartografia Imaginária da Tríplice Fronteira. São Paulo: Dobra Editorial, p. 117-138, 2014.

GONZÁLEZ, RAMPELLO y DOMÍNGUEZ. Impactos socio-territoriales: Puerto Iguazú y Reserva Iriapú, 600 hectáreas. Misiones, Argentina, 2017.

SANTOS, José Carlos. Uma leitura micro da tríplice fronteira Brasil, Paraguai e Argentina. Florianópolis, SC, 2015.

SHOHAMY, E.; GURTER, D. Linguistic Landscape: Expanding the Scenery. Routledge: Oxon, 2009.

SILVA, Izabel da; SANTOS, Maria Elena Pires; JUNG, Neiva Maria. Multilinguismo e política linguística: análise de uma paisagem linguística transfronteiriça. Revista Domínios da Lingu@gem. Uberlândia, vol. 10 no 4 out/dez.2016, p. 12571277.

SOARES, LOMBARDI, SALGADO. Paisagem linguística e repertórios em tempos de diversidade: uma situação em perspectiva. Revista Calidoscópio, Vol. 14, n. 2, p. 209-218, 2016.

VERA, N. y VALENZUELA, M. El concepto de identidad como recurso para el estudio de transiciones. Psicologia y Sociedade, 2012. Acceso en 15 de abril, 2020, en http://www.scielo.br/pdf/ psoc/v24n2/03.pdf.

VERTOVEC, S. (2007). Super-diversity and its implications. Ethnic and Racial Studies, 30(6), 10241054. Disponible en: <ttp://www.informaworld. $\mathrm{com} / \mathrm{smpp} /$ title $\sim$ content $=\mathrm{t} 713685087>$.

RODRIGUEZ, P. El paisaje lingüístico de Sevilla. diputación de Sevilla, 2012.

SRHIR y ADIL. 2018. "Recontextualización sociolingüística y Superdiversidad. El árabe en el paisaje lingüístico del barrio de Lavapiés en Madrid”. Lingue e Linguaggi 25: 197-225. 
SRHIR, M. Dos décadas de estudios del Paisaje Lingüístico: enfoques teórico-metodológicos y nuevos desafíos en la investigación. Revista Signo y Seña, 2019. ISSN 2314-2189.

Submissão: junho de 2020.

Aceite: setembro de 2020 . 